\title{
NANOCOMPOSITES TRANSFORMED FROM POLYSTYRENE WASTE/ANTIMONY, BARIUM AND NICKEL OXIDES NANOPARTICLES WITH IMPROVED THERMAL AND ELECTRICAL PROPERTIES
}

\author{
Y. T. Sabo, D. E. A. Boryo, I. Y. Chindo and A. M. Auwal. \\ Department of Chemistry, Abubakar Tafawa Balewa University, Bauchi, Nigeria \\ Corresponding author: sabotakkoy@gmail.com, +2348064754475,+2348122217954
}

\begin{abstract}
In this experiment, the oxide nanoparticles were synthesized via chemical precipitation and the nanocomposites were produced using in situ polymerization method with varying nanoparticles contents ranged from $0.1 \mathrm{~g}$ to $1.0 \mathrm{~g}$ for electrical conductivity and from $0.05 \mathrm{~g}$ to $0.25 \mathrm{~g}$ for thermal conductivity. The electrical and thermal conductivities of nanocomposites were investigated and compared with the values obtained for untreated polystyrene. It was observed that the electrical and thermal properties were higher for the nanocomposites and increase with increasing nanoparticle concentrations in the samples. It can be observed that nanocomposite containing $\mathrm{NiO}$ nanoparticles gave a better electrical and thermal conductivity followed by nanocomposite containing $\mathrm{BaO}$ nanoparticles and nanocomposite containing $\mathrm{Sb}_{2} \mathrm{O}_{3}$ nanoparticles respectively. It can also be observed that nanocomposite containing $\mathrm{NiO}$ nanoparticle showed increase in rate of heat transfer from $1.60 \mathrm{~W}$ to $2.60 \mathrm{~W}$, while nanocomposite containing $\mathrm{BaO}$ nanoparticles recorded increase in rate of heat transfer from $1.40 \mathrm{~W}$ to $2.45 \mathrm{~W}$ and nanoomposite containing $\mathrm{Sb}_{2} \mathrm{O}_{3}$ nanoparticle showed increase in rate of heat transfer from $1.07 \mathrm{~W}$ to $2.21 \mathrm{~W}$, as concentration of nanoparticles increased from $0.05 \mathrm{~g}$ to $0.25 \mathrm{~g}$ respectively. Conclusively, with these results, the nanocomposite containing $\mathrm{NiO}$ nanoparticles gave a better thermal and electrical conductivity by having a better conducting filler network inside the matrix than nanocomposite containing BaO nanoparticles and nanocomposite containing $\mathrm{Sb}_{2} \mathrm{O}_{3}$ nanoparticles. It is recommended that during the production of polymer nanocomposite, $\mathrm{PS} / \mathrm{NiO}, \mathrm{PS} / \mathrm{BaO}$ and $\mathrm{PS} / \mathrm{Sb}_{2} \mathrm{O}_{3}$ nanocomposites could be used in electrically conductive devices as well as suitable materials for heat transfer applications.
\end{abstract}

Keywords: Polystyrene, nanoparticles, nanocomposites, electrical conductivity, thermal conductivity.

\section{INTRODUCTION}

Polystyrene is an amorphous thermoplastic polymer that softens at relatively low temperatures and it flows like a liquid at 100 ${ }^{\circ} \mathrm{C}$ or under stress, making it easy to thermoform or extrude ${ }^{1}$ Service temperatures can be lowered under stress because of modulus decay, creep, strain, relaxation, etc ${ }^{2}$. The presence of phenyl groups is responsible for the relatively high 
glass transition temperature $(T \mathrm{~g})$ and high refractive index value (about 1.57 to 1.6). Polystyrene has density of $1.05 \mathrm{~g} / \mathrm{cm}^{3}$, which is higher than density of polyethylene and polypropylene. It does not have a sharp melting point because it is amorphous. This is observed in gradual softening of the material over a wide range of temperatures. The $T \mathrm{~g}$ of the polystyrene is between $74{ }^{\circ} \mathrm{C}$ and $105{ }^{\circ} \mathrm{C}$, and below its $\mathrm{Tg}$, polystyrene is hard and brittle ${ }^{3}$.

Isotactic polystyrene is a semi-crystalline polymer with a melting point of around 240 ${ }^{\circ} \mathrm{C}$, its crystallization rate is too slow to be used in injection molding. Syndiotactic polystyrene, where phenyl groups are placed on alternating sides of the polymer chain, has much faster crystallization rate than that of isotactic polystyrene. Atactic polystyrene which has randomly distributed phenyl groups on both sides of the hydrocarbon backbone and consequently no crystallinity, is the most commercially significant isomer of polystyrene ${ }^{3}$. The disposal of polystyrene wastes creates environmental contamination due to their non-biodegradable nature ${ }^{7}$. Polystyrene is also quite often used as polymer matrix for the preparation of polymer based nano composites. Polymer nanocomposites are hybrid organicinorganic materials with at least one dimension of the filler phase less than $100 \mathrm{~nm}$.

The increscent growth in the amount of polystyrene wastes into the environment is due to the booming development of electronic products. The disposal of polystyrene wastes creates environmental pollution and contamination due to their nondegradable nature. Scientific research had shown that the solution to these problems is achieved through recycling method and transforming them to smart and useful materials. This research work desires to provide information on transforming polystyrene wastes to nanoproducts with improved electrical and thermal properties for possible application in electronic appliances, automobiles and as suitable materials heat transfer applications. Apart from the numerous advantages of polystyrene in buildings, electronics and other applications, situations where polystyrene wastes are recycled and transformed into useful materials are rarely found. Transforming polystyrene wastes to useful materials reduce the effects of environmental pollutants on animals, plants and humans. It also prevents wastes from entering into landfills and site containing wastes. The negligence of transforming polystyrene wastes to useful materials has attracted a lot 
of attention in the field of research whereas, the recycling of polymers to nanoproducts with improved electrical and thermal properties has not been adequately studied. Therefore, this research work will bring about knowledge that is of utmost importance in the field of research.

The aim of this research is to convert polystyrene wastes to nanoproducts with electrical and thermal properties. The objective of this research is to produce polystyrene nanocomposite with improved electrical and thermal properties for possible application in electronic appliances, automobiles and as suitable materials for heat transfer application.

Nanoparticles were considered to have a size range between 1 and $100 \mathrm{~nm}^{8}$ ). However, it has been shown that particles larger than 50 $\mathrm{nm}$ show no significant properties of materials as expected ${ }^{8}$.

Research had shown that the term "nanoparticle" is not usually applied to individual molecules; it usually refers to inorganic materials. Nanoparticles are particles between 1 and 100 nanometres (nm) in size with a surrounding interfacial layer. The interfacial layer is an integral part of nanoscale matter, fundamentally affecting all of its properties. The interfacial layer typically consists of ions, inorganic and organic molecules. Nanoparticles are of great scientific interest as they are, in effect, a bridge between bulk materials and atomic or molecular structures ${ }^{4}$. A bulk material should have constant physical properties regardless of its size, but at the nano-scale sizedependent properties are often observed. Thus, the properties of materials change as their size approaches the nanoscale and as the percentage of the surface in relation to the percentage of the volume of a material becomes significant. For bulk materials larger than one micrometer (or micron), the percentage of the surface is insignificant in relation to the volume in the bulk of the material. The interesting and sometimes unexpected properties of nanoparticles are therefore largely due to the large surface area of the material, which dominates the contributions made by the small bulk of the material.

Research had shown that nanocomposites are composites in which at least one of the phases show dimensions in the nanometre range (1 $\left.\mathrm{nm}=10^{-9} \mathrm{~m}\right)^{14}$. Nanocomposite materials have emerged as suitable alternatives to overcome limitations of micro composites and monolithic, while posing preparation challenges related to the control of elemental composition and stoichiometry in the nanocluster phase ${ }^{14}$. It is reported to be the 
materials of 21 st century in the view of possessing design uniqueness and property combinations that are not found in conventional composites ${ }^{14}$.

Many polymers are electrically insulating, but the conductive metal nanoparticles provide an acceptable conductivity in polymer/metal nanocomposites. The need for flexible, lightweight, electrically conductive devices led to the generation of smart materials called conductive polymer nanocomposites (CPCs). The electrical conductivity can be obtained based on the formation of charge transfer complexes inside the polymer chain network, due to the addition of metal nanoparticles using a twopoint probe (continuity test) analysis ${ }^{13}$. The conductive nanocomposites can be used in various applications such as rechargeable batteries, electrodes, shields, sensors, etc ${ }^{13}$. According to Vijayakumari et al., ${ }^{16}$ poly methyl(methacrylate)/copper (PMMA/Cu) nanocomposite was synthesized by in situ polymerization method. The electrical conductivity of the polymer nanocomposite was determined by using four-point probe method. The result showed that the conductivity of the polymer (PMMA) was increased by increasing the metal nanoparticles $(\mathrm{Cu})$ concentrations and the conductivity was measured in $\mathrm{mS} / \mathrm{cm}$. The result showed that nanocomposite containing $0.20 \mathrm{~g}$ of $\mathrm{Cu}$ nanoparticles gave conductivity of $0.398 \mathrm{mS} / \mathrm{cm}$, and at $0.25 \mathrm{~g}$ concentration, the conductivity was $1.880 \mathrm{mS} / \mathrm{cm}$.

In addition to engineering polymer chains and morphology at the atomic/molecular level, the thermal conductivity of polymers can also be enhanced by adding highly thermal conductive fillers. Although the composites incorporated with macro- or micro-fillers have already been widely studied for close to a century using the effective medium theory, the thermal conductivity of composites filled with nanofillers can be quite different and not well understood yet ${ }^{11,}{ }^{17}$. Different from the macro- or micro-scale composites, the large specific surface area of nano-fillers can lead to large contribution of interfacial thermal resistance in a nanocomposite. In addition, it is very challenging to mathematically describe the heat conduction if nano-fillers form a network in a nanocomposite. The thermal conductivity is determined not only by the polymer matrix and the fillers, but also the interaction between filler and matrix and among fillers ${ }^{11,17}$.

The high thermally conductive ceramic fillers are more preferable for not only their electrical insulation properties but also thermal stabilities. Typical high thermal 
conductivity ceramic nano-fillers are magnesium oxide $(\mathrm{MgO})$, aluminium oxide $\left(\mathrm{Al}_{2} \mathrm{O}_{3}\right)$, silicon nitride $\left(\mathrm{Si}_{3} \mathrm{~N}_{4}\right)$, silicon carbide $(\mathrm{SiC})$, zinc oxide $(\mathrm{ZnO}) 6,{ }^{18}$. Compared with the metallic and ceramic fillers, nanostructured carbon fillers have attracted more intensive interests because of their high thermal conductivity. For example, expanded graphite (EG) has a thermal conductivity of about $300 \mathrm{~W} \mathrm{~m} \mathrm{~m}^{-1} \mathrm{~K}^{-1}$. Graphene nanoplate (GNP) possesses a thermal conductivity as high as $1000-5000$ $\mathrm{W} \cdot \mathrm{m}-1 \cdot \mathrm{K}-1$ 10, 15 . Carbon nanotubes are regarded as the most promising candidates owing to their high mechanical strength, chemical stability and high thermal conductivity of $1000 \sim 3000 \mathrm{~W} \mathrm{~m}^{-1} \mathrm{~K}^{-1} 19$.

Te high density polyethylene/ copper oxide nanocomposites were placed in a thermal conductivity test apparatus and two suitable temperatures were maintained on the disc and the samples. The thermal conductivity was calculated using steady state heat conduction technique ${ }^{9}$.

\section{MATERIALS AND METHODS}

\section{Materials}

The materials used include retort stand, razor blade, lighter, stopwatch, magnetic stirrer JB4A, analytical weighing balance JT 2003A.

\section{Collection of Polystyrene Wastes}

Polystyrene waste samples were collected from a refuse dump site located at latitude $10^{\circ} 17^{\prime} 57^{\prime \prime} \mathrm{N}$ and longitude 9050'06"E Jahun in Bauchi State Nigeria.

\section{Chemicals and Reagents}

In this work or research, the nanoparticles of $\mathrm{NiO}, \mathrm{BaO}$ and $\mathrm{Sb}_{2} \mathrm{O}_{3}$ used were synthesized in the Laboratory of Department of Chemistry, Abubakar Tafawa Balewa University, Bauchi. The solvents and reagents used were obtained in the laboratory and were of great analytical reagent grade such as ethanol (Emerk Darmstadt company), toluene (BDH Laboratory reagent), methanol (Emerk Darmstadt company), sodium hydroxide (Kermel), sodium bicarbonate (Kermel Company), nickel sulphate (AR Guandong Chemicals), barium nitrate (JHD Company), antimony trichloride (Tited Biotech Ltd).

\section{Methods}

\section{Dissolution of Polystyrene (PS)}

In this experiment, the method reported by [1] was adopted. The polystyrene wastes were rinsed off and washed several times with detergent and water to remove any food or dirt particles and dried in the laboratory. The samples (PS wastes) were crushed so that they can be fit into the container. Polystyrene waste $(4 \mathrm{~g})$ was dissolved in $20 \mathrm{~cm}^{3}$ of toluene 
(solvent) in a conical flask and stirred for 30 minutes using magnetic stirrer of model JB4A. The solution was then allowed to be heated for 30 minutes at $60{ }^{\circ} \mathrm{C}$ to form a solution.

\section{Preparation of Nanoparticles Preparation of BaO Nanoparticles} In this research, a wet chemical precipitation method was used to obtain the metal oxide nanopaticles. Sodium bicarbonate $(0.4 \mathrm{M})$ was added to the $0.2 \mathrm{M}$ solution of barium nitrate drop wise, under constant stirring for 2 hours until addition of sodium bicarbonate solution was complete. After the completion of the reaction, the precipitates formed were allowed to settle overnight. The solution was filtered off and washed several times with distilled water until free from excess bicarbonate. A white precipitate formed was then allowed to dry in oven at $80{ }^{\circ} \mathrm{C}$ for 1 hour and then calcined at $150{ }^{\circ} \mathrm{C}$ for 3 hours to form the desired barium oxide nanoparticles.

\section{Preparation of NiO Nanoparticles}

A solution of nickel sulphate $(1.0 \mathrm{~L}, 0.11 \mathrm{M})$ was taken and aqueous ammonia was added drop wise with constant stirring using magnetic stirrer of model JB-4A until the $\mathrm{pH}$ of 10 was reached. The precipitate formed was filtered and washed several times with distilled water. The precipitate formed was allowed to dry in oven at $70{ }^{\circ} \mathrm{C}$ for 24 hours and calcined at $600{ }^{\circ} \mathrm{C}$ in a muffle furnace for 5 hours to form the desired nickel oxide nanoparticles.

\section{Preparation of $\mathrm{Sb}_{2} \mathrm{O}_{3}$ Nanoparticles}

$0.1 \mathrm{M}$ solution of antimony trichloride was dissolved in $500 \mathrm{~cm}^{3}$ of ethylene glycol under vigorous stirring to form a transparent solution. Subsequently, $500 \mathrm{~cm}^{3}$ of distilled water was added to the solution and stirred for 15 minutes, $6 \mathrm{M}$ solution of sodium hydroxide $(\mathrm{NaOH})$ was added to adjust the $\mathrm{pH}$. The whole solution was stirred for 20 minutes before transferring it into an autoclave at $120{ }^{\circ} \mathrm{C}$. After 12 hours, the product formed was centrifuged and washed several times with distilled water and ethanol and then dried at $60{ }^{\circ} \mathrm{C}$ for 6 hours to obtained the required antimony oxide nanoparticles $\left(\mathrm{Sb}_{2} \mathrm{O}_{3}\right)$.

\section{Determination of Electrical Conductivity}

The electrical conductivity of the nanocomposites was determined using 2 Probe Digital Multimeter DT 9205A. The concentrations of nanoparticles were varied as $0.1 \mathrm{~g}, 0.2 \mathrm{~g}, 0.3 \mathrm{~g}, 0.4 \mathrm{~g}, 0.5 \mathrm{~g}, 0.6 \mathrm{~g}, 0.7 \mathrm{~g}$. $0.8 \mathrm{~g}, 0.9 \mathrm{~g}$ and $1.0 \mathrm{~g}$ respectively and polystyrene solution was constantly maintained as $10 \mathrm{ml}$. The black test lead was 
inserted into the COM jack and the red lead into the $V \Omega$ jack. The test leads were connected across the formulated nanocomposites and a beep sound was produced showing that conductivity was detected.

\section{Determination of thermal conductivity}

The method reported by [9] was adopted to determine the rate of heat transfer. The formulated nanocomposites were prepared as round disc form the sheet and were placed in the thermal conductivity test apparatus. Suitable two different temperatures were maintained on the disc and the samples were placed in between them. Based on the temperatures measured after standard time period, the rate of heat transfer was calculated using a steady-state heat conduction technique. The rate of heat transfer was calculated using the formula;

$$
Q(W)=\frac{K A D T}{D x}
$$

Where Q Is the rate of heat transfer, DT is the temperature difference, Dx, thickness, $\mathrm{A}$ is the surface area of the material and $\mathrm{K}$ is the thermal conductivity constant of the material $=0.0038 \mathrm{~W} / \mathrm{mK}$

The surface area was calculated using the formula, $\mathrm{A}=2 \pi r l\left(\mathrm{~m}^{2}\right)$

$\mathrm{T}_{2}$ and $\mathrm{T}_{1}$ are the temperatures at the hot end and the cold end respectively DT $=\mathrm{T}_{2}-\mathrm{T}_{1}$.

1 is the length of the material and $r$ as the radius in meter.

The radius was determined using the formula.

Radius $(r)=\frac{\text { Diamter }}{2}$

Where diameter is measured in $(\mathrm{m})$, the length and thickness of the material were determined using a ruler and vernier calliper. 


\section{RESULTS AND DISCUSSION}

Electrical Conductivity of Formulated Nanocomposites

Table 1: Electrical Conductivity of Formulated Nanocomposites.

\begin{tabular}{|c|c|c|c|c|}
\hline \multirow{2}{*}{$\begin{array}{l}\text { Amount of nanoparticles } \\
\text { Incorporated into PS (g) }\end{array}$} & \multicolumn{4}{|c|}{ Electrical Conductivity (mS/cm) } \\
\hline & Untreated $P s$ & PS/NiO & PS/BaO & $\mathbf{P S} / \mathrm{Sb}_{2} \mathrm{O}$ \\
\hline 0.0 & 1 & - & - & - \\
\hline 0.1 & & 1 & 1 & 1 \\
\hline 0.2 & & 1 & 1 & 1 \\
\hline 0.3 & & 1 & 1 & 1 \\
\hline 0.4 & & 1 & 1 & 1 \\
\hline 0.5 & & .01 and sound & 1 & 1 \\
\hline 0.6 & & .01 and sound & 1 & 1 \\
\hline 0.7 & & .01 and sound & 0.01 and sound & 1 \\
\hline 0.8 & & .01 and sound & 0.01 and sound & 1 \\
\hline 0.9 & & .01 and sound & 0.01 and sound & 1 \\
\hline 1.0 & & .01 and sound & 0.01 and sound & 0.01 and sound \\
\hline
\end{tabular}

The result showing the electrical conductivity of the formulated nanocomposites is shown in Table 1 above. From Table 1 above, it was observed that untreated polystyrene (PS) showed 1 (that is no conductivity). From Table 1 above, it can also be observed that nanocomposite containing $\mathrm{NiO}$ nanoparticle began to show conductivity at $0.5 \mathrm{~g}$ nanoparticle concentration thereby producing a beep sound. The result also revealed that nanocomposite containing $\mathrm{BaO}$ nanoparticles began to show conductivity at $0.7 \mathrm{~g}$ nanofiller concentration while nanocomposite containing $\mathrm{Sb}_{2} \mathrm{O}_{3}$ nanoparticle showed conductivity at $1.0 \mathrm{~g}$ nanofiller content. The overall results showed that nanocomposite containing $\mathrm{NiO}$ nanoparticles gave a better electrical conductivity followed by nanocomposite containing $\mathrm{BaO}$ nanoparticles and nanocomposite containing $\quad \mathrm{Sb}_{2} \mathrm{O}_{3}$ nanoparticles respectively. This may be due to the fact that $\mathrm{Ni}$ is a transition metal; it has more electrical conductivity while $\mathrm{Ba}$ is an alkali metal and $\mathrm{Sb}$ a metalloid. 
This result conforms to the result obtained by [16] that nanocomposite containing $0.20 \mathrm{~g}$ of $\mathrm{Cu}$ nanoparticles gave conductivity of 0.398 $\mathrm{mS} / \mathrm{cm}$, and at $0.25 \mathrm{~g}$ concentration, the conductivity was $1.880 \mathrm{mS} / \mathrm{cm}$. The result showed that the conductivity of the polymer
(PMMA) was increased by increasing the metal nanoparticles $(\mathrm{Cu})$ concentrations.

\section{Thermal Conductivity of Formulated} Nanocomposites

The result showing the rate of heat transfer of the nanocomposites produced is shown in Figure 1 below.

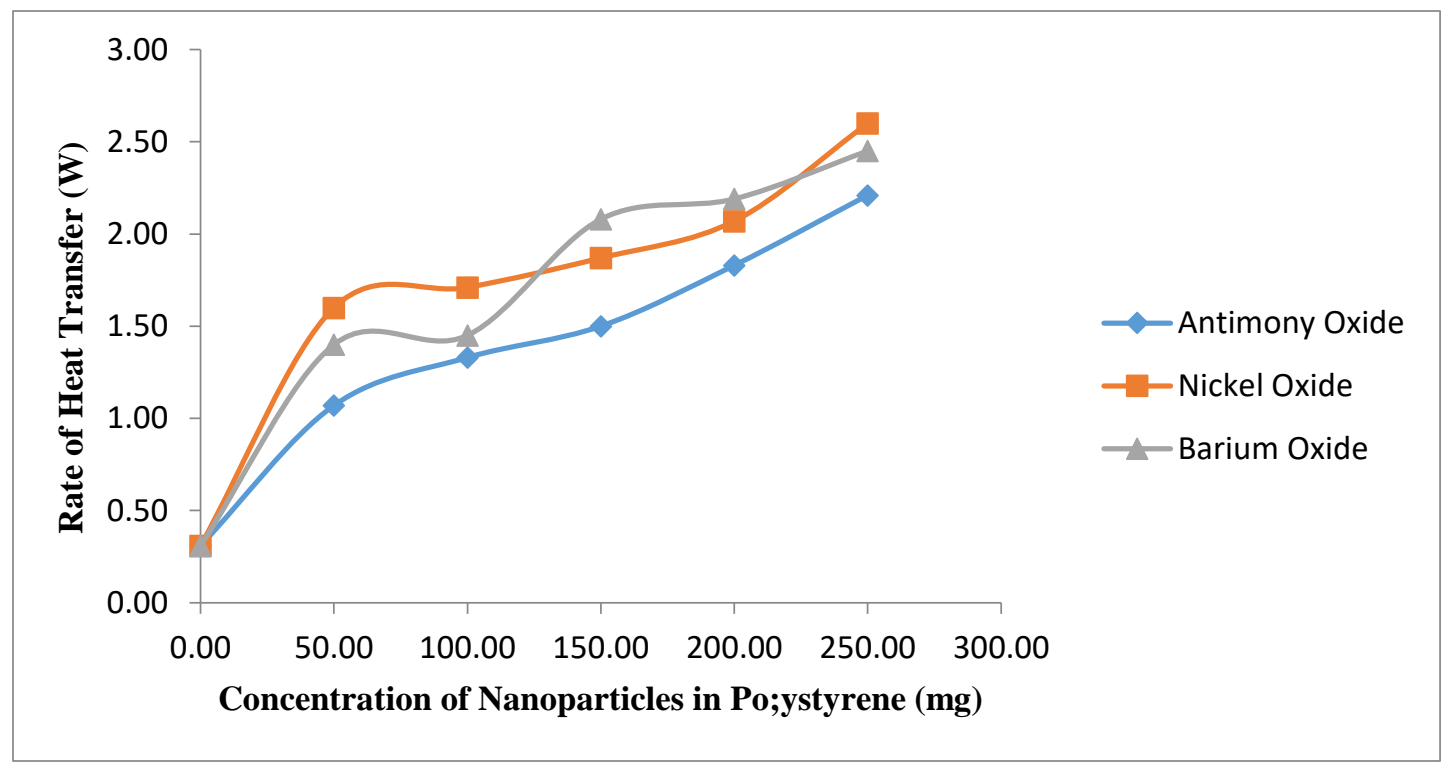

Figure 1: Effect of Concentration of Nanoparticles on Rate of Heat Transfer of Formulated Nanocomposites

From Figure 1 above, it can be observed that untreated polystyrene showed a rate of heat transfer of $0.31 \mathrm{~W}$. The result in Figure 1 revealed that nanocomposite containing $\mathrm{NiO}$ nanoparticle showed increase in rate of heat transfer from $1.60 \mathrm{~W}$ to $2.60 \mathrm{~W}$, as concentration of $\mathrm{NiO}$ nanoparticles increased from $50.00 \mathrm{mg}$ to $250.00 \mathrm{mg}$. It also showed that nanocomposite containing $\mathrm{BaO}$ nanoparticles recorded increase in rate of heat transfer from $1.40 \mathrm{~W}$ to $2.45 \mathrm{~W}$ with increasing nanofiller concentration from $50.00 \mathrm{mg}$ to $250.00 \mathrm{mg}$ while nanoomposite containing $\mathrm{Sb}_{2} \mathrm{O}_{3}$ nanoparticle showed increase in rate of heat transfer from $1.07 \mathrm{~W}$ to $2.21 \mathrm{~W}$, as concentration of nanoparticles increased from $50.00 \mathrm{mg}$ to $250.00 \mathrm{mg}$ respectively.

The overall result showed that nanocomposite containing $\mathrm{NiO}$ nanoparticles 
gave a better thermal conductivity by having a better conducting filler network inside the matrix than nanocomposite containing $\mathrm{BaO}$ nanoparticles and nanocomposite containing $\mathrm{Sb}_{2} \mathrm{O}_{3}$ nanoparticles. This may be due to the fact that $\mathrm{Ni}$ is a transition metal; has a better thermal conductivity than $\mathrm{Ba}$ an alkali earth metal and $\mathrm{Sb}$ a metalloid.

This result conforms to the result obtained by [9] that the addition of $\mathrm{CuO}$ nanofiller increases the conducting network within polyethylene (matrix)

\section{CONCLUSION}

Based on the present findings, it can be concluded that $\mathrm{PS} / \mathrm{NiO}, \mathrm{PS} / \mathrm{BaO}$ and $\mathrm{PS} / \mathrm{Sb}_{2} \mathrm{O}_{3}$ nanocomposites were produced. It can also be concluded that $\mathrm{PS} / \mathrm{NiO}, \mathrm{PS} / \mathrm{BaO}$ and $\mathrm{PS} / \mathrm{Sb}_{2} \mathrm{O}_{3}$ nanocomposites have improved electrical and thermal properties which increased as the concentration of the nanoparticles incorporated into the polymer matrix increased. It can be concluded that nanocomposite containing $\mathrm{NiO}$ nanoparticles gave a better electrical and thermal conductivities followed by nanocomposite containing $\mathrm{BaO}$ nanoparticles and nanocomposite containing $\quad \mathrm{Sb}_{2} \mathrm{O}_{3}$ nanoparticles. It is recommended that during the production of polymer nanocomposites, $\mathrm{PS} / \mathrm{Sb}_{2} \mathrm{O}_{3}, \quad \mathrm{PS} / \mathrm{BaO}$ and $\mathrm{PS} / \mathrm{NiO}$ nanocomposites can be used in electrically conductive devices and as suitable materials for heat transfer applications,

\section{REFERENCES}

[1] Achilias D.S., Antonakou W., Koustsokosta E., and Lappas A. (2009) Chemical Recycling of Polymers from WEEE. Journal of Applied Polymer Science. 114(6): 212-221

[2] Biron, M. (2007). Thermoplastics and thermoplastic composites; Butterworth-Heinemann, Elsevier: Oxford, UK.

[3] Cole, L. [Ed.] (2014). Polystyrene Synthesis, Characterization and Application. New York; Nova Publishers, Inc. Pp 1-2, 205-206, 201212, 213-230.

[4] Heinzerling P., and Oetken M. (2018). Nanochemistry- A split between $18^{\text {th }}$ Century and Modern Times. World Journal of Chemical Education. 6(1):1-7

[5] Kim, H.S., Kim, J.H., Kim, W.Y., Lee, H.S., Kim, S.Y., and Khil, M.S. (2017). Volume control of expanded graphite based on inductively coupled plasma and enhanced thermal conductivity of epoxy composite by formation of the filler network. Carbon. 119: 40-46.

[6] Lee, S.H., and Choi, Y. (2013). Electrophysical properties of composites with nano-sized oxides. Journal of Nanoscience and Nanotechnology. 13: $7610-7614$ 
[7] Maharana, T., Negi, Y. S. and Mohanty, B. (2007) 'Review Article: Recycling of Polystyrene. Polymer-Plastics Technology and Engineering, 46: 7, $729-736$.

[8] Mittal, V. (2010) in Optimization of Polymer Nanocomposite Properties (ed. V. Mittal), Wiley-VCH Verlag $\mathrm{GmbH}$ and Co. KGaA, Weinheim, pp. $1-19$.

[9] Muthiah, C. T., and Marimuthu, P. (2016). Experimental Study of Thermal Conductivity of Polyethylene Copper Oxide Nanocomposite. International Journal of Advanced Engineering Technology. 7(1): 937-941

[10] Nair, R.R., Blake, P., Grigorenko, A.N., Novoselov, K.S., Booth, T.J., Stauber, T., Peres, N.M.R., and Geim, A.K. (2008). Fine structure constant defines visual transparency of graphene, Science, 320: 1308

[11] Nan, C.W., Birringer, R., Clarke, D. R., and Gleiter, H. (1997). Effective thermal conductivity of particulate composites with interfacial thermal resistance, Journal of Applied Physics. 81: $66-92$

[13] Novikov, V.V., Friedrich, C., and Nezhevenko, K. A. (2009). Electrical Conductivity of Nanocomposites. Science and Engineering of Composite Materials. 16(1): 1-20

[14] Schmidt, D, Shah, D., Giannelis, E. P. (2002). New advances in polymer/layered silicate nanocomposites. Current Opinion in Solid State \& Materials Science. 6(3):205-212.

[15] Shahil, K.M., and Balandin, A.A. (2012). Graphene Multilayer graphene nanocomposites as highly efficient thermal interface materials. Nano Letters. 12: 861-867

[16] Vijayakumari G., Selvakumar N., Jeyasubramanian K., and Mala R.(2013). Investigation on the Electrical Properties of Polymer Metal Nanocomposites for Physiological Sensing Applications. Physics Procedia. 49:67-78

[17] Wang, X.J., Zhang, L.Z., and Pei, L.X. (2014). Thermal conductivity augmentation of composite polymer materials with artificially controlled filler shapes. Journal of Applied Polymer Science. 131(8): 39550.

[18] Yoshihara, S., Tokita, M., Ezaki, T., Nakamura, M., Sakaguchi, M., Matsumoto, K., and Watanabe, J. (2014). Main chain liquid crystalline polymer exhibiting unusually high thermal conductivity in an isotropic composite. Journal of Applied Polymer Science. 131(6): 39896

[19]. Yu, C., Shi. L., Yao, Z., Li, D., and Majumdar, A. (2005). Thermal conductance and thermopower of an individual single wall carbon nanotube. Nano Letters. 5: 18421846. 
